\title{
Climate and Environment during the Last Deglaciation and the Holocene in NW Russia and around the Baltic
}

\author{
St. Petersburg, Russia, 27 March - 2 April, 2001
}

In a beautiful old palace on the southern shore of the Gulf of Finland, researchers from Sweden, Finland, Denmark, Estonia and Russia presented the results of their scientific network project. The Nordic Council of Ministers (www.norden.org) provided funding, enabling the participation of a number of Russian, Swedish and Finnish Ph.D. students and the workshop was organized by the Institute of Limnology, Russian Academy of Sciences, St. Petersburg, together with Lund University, Sweden, and Helsinki University, Finland. More than 60 participants from the UK, Norway, Sweden, Finland, Estonia and Russia took part in the meeting, which was divided into three oral sessions and several poster sessions.

The network project started in 1996, with the objective of using lake sediment analyses to reconstruct environmental changes in NW Russia during the last 15,000 years. The project is mainly financed by the Swedish Institute, the Royal Swedish Academy of Science and the Swedish Natural Science Research Council. Lake sediments were retrieved along a NW-SE transect in regions such as the Kola Peninsula, eastern Russian Karelia, the Karelian Isthmus, the Valdai hills and the Rostov-Jaroslavl' area north of Moscow. To summarize the research results which have been obtained so far, and to compare them with other ongoing research projects, the workshop addressed two major themes: (1) Late Quaternary environmental and climatic changes in NW Russia and around the Baltic Sea, and (2) Baltic Sea development.

J. Lowe (UK) explained the initiatives and proposals of the INTIMATE group (INTegration of Ice-core, MArine and TErrestrial records, www.geog.uu.nl/fg/ paleoclimate/intimate) and discussed how a close collaboration between the NW Russian science

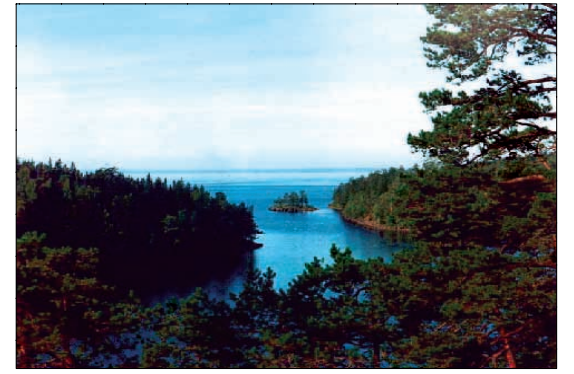

View of Lake Ladoga from the Valaam Island

communities and the INTIMATE project group could be of mutual benefit for improving understanding of the rapid environmental changes around the North Atlantic region during the Last Glacial-Interglacial transition. Lake sediment studies have a long tradition in Russia. The Institute of Limnology (Russian Academy of Science, St. Petersburg) has been involved in paleolimnological research in many regions of the former Soviet Union since the 1950s. D. Subetto and N. Davydova (Russia) gave a historic overview of the Institute's research program, which has involved the study not only of lakes close to St. Petersburg (Lakes Ladoga, Onega and II'men), but also of lakes on the Kola Peninsula, in the Bol'shezemelskaya tundra, in the Urals, in Kazakhstan, in Kirgizyia, as well as in high mountain areas in the Caucasus, the Pamir, Tien-Shan and Mongolia.

A special session was devoted to the results of the joint SwedishRussian project. B. Wohlfarth gave an overview on the present state of the project, which was followed by individual presentations of some of the scientists involved. It was noted that the application of a multi-proxy approach in studying the different lake sites led to the discovery of the Vedde Ash on the Karelian Isthmus and to a complex regional picture of environmental development during the deglaciation and early Holocene.

An attempt to understand the timing of the Littorina transgressions in the southern Baltic
Sea included presentations of ongoing paleoecological studies in Ingermanland, NW Russia. In this area, Littorina transgression phases $(8,000-4,000 \mathrm{BP})$ are being studied and the timing and significance of the observed phases are beingcompared to the south-western and southern Baltic (Själland in Denmark and Blekinge in Sweden). The importance of a uniform sampling strategy and analytical methodology was emphasized.

This very successful meeting, which would not have been possible without the help of the staff and Ph.D. students from the Institute of Limnology and students from St. Petersburg State University (T. Sapelko, D. Kuznetsov, O. Vinogradova, D. Maksimov, A. Maksimova, E. Sikatskaya), certainly helped to establish many new contacts to bridge the gap between Russian and Scandinavian science. Hopefully, young students will now take advantage of these contacts, so that a student exchange programme can gradually be built up. Special thanks go to S. Slotina for organizing the cultural highlights, for professional guidance in St. Petersburg and for help and assistance throughout the conference.

An abstract volume of the lectures and posters is available from the Institute of Limnology, RAS, St. Petersburg.

\section{Dmitry Subetro}

Institute of Limnology, Academy of Sciences St.Petersburg, Russia Subetto@ds5544.spb.edu

\section{Barbara Wohlfarth}

Dept. of Quaternary Geology, Lund University, Lund, Sweden Barbara.Wohlfarth@geol.lu.se

\section{HANNU HyväRINEN \\ Dept. of Geology, Helsinki University Helsinki, Finland Hannu.Hyvarinen@helsinki.fi}

